\title{
TECENDO VIAS DE SUPERAÇÃO DOS DANOS GERADOS PELO TRANSTORNO MENTAL
}

\section{Priscila Maria Marcheti}

Universidade Federal do Mato Grosso do Sul

Alexandra Ayach Anache

Universidade Federal do Mato Grosso do Sul
Recebido em: 23/03/2020

$1^{\text {a }}$ revisão em: 24/03/2020

Aceito em: 02/04/2020

\section{RESUMO}

O artigo visa identificar o movimento da subjetividade no processo de superação dos danos gerados pelo transtorno mental no processo de participação de uma oficina terapêutica. A subjetividade consiste em um sistema complexo de produção simbólico-emocional diante de situações vividas pelos indivíduos, associando dialeticamente as dimensões individual e social, os quais permitem a produção de sentidos subjetivos. Para tal, foi realizado um estudo de caso de uma mulher que participou por 10 semanas de uma oficina terapêutica de bordado no Centro de Atenção Psicossocial. As inter(invenções) construídas junto com a participante foram promovendo condições para a elaboração de novos sentidos subjetivos das situações que geraram danos na sua vida, as quais foram constitutivas da sua subjetividade. Essas mudanças foram identificadas na qualidade das suas relações familiares e nas relações de trabalho, logo contribuíram para o fortalecimento da qualidade de sua vida.

Palavras-chave: teoria da subjetividade; mulheres; educação; psicologia. 


\title{
NEEDLEWORKING WAYS OF OVERCOMING OF DAMAGE GENERATED BY MENTAL DISORDER
}

\begin{abstract}
The article aims to identify the movement of subjectivity in the process of overcoming the damage caused by mental disorder in the process of participation of a therapeutic workshop. Subjectivity consists of a complex system of symbolic-emotional production before situations lived by individuals, associating dialectically the individual and social dimensions, which allow the production of subjective senses. Therefore, a case study was conducted of a woman who participated for 10 weeks in a needlework therapeutic workshop at the Psychosocial Care Center. The interventions built together with the participant was promoting conditions for the elaboration of new subjective senses of situations that caused damage to her life, which were constitutive of her subjectivity. These changes were identified in the quality of her family and work relationships, soon contributed to the strengthening of the quality of her life.
\end{abstract}

Keywords: subjectivity theory; women; education; psychology. 


\section{TEJER MANERAS DE SUPERAR EL DAÑO GENERADO POR EL TRASTORNO MENTAL}

\section{RESUMEN}

Este trabajo trata de identificar los movimientos de subjetividad en el proceso de superación de los problemas generados por trastorno mental a lo largo de la participación en un taller terapéutico. La subjetividad consiste en un sistema complejo de producción simbólico emocional ante situaciones vividas por los individuos, asociando de forma dialéctica las dimensiones individual y social, lo que permite la producción de sentidos subjetivos. Para ello fue realizado un estudio de caso con una mujer que participó en un taller terapéutico de bordado en el Centro de Atención Psicosocial durante 10 semanas. Las intervenciones con la participante fueron promoviendo condiciones para la elaboración de nuevos sentidos subjetivos de las situaciones que generaban daño en su vida y que dieron origen a su subjetividad. Esos cambios fueron identificados en la calidad de sus relaciones familiares y en las relaciones de trabajo que posteriormente ayudaron a la mejora de su calidad de vida.

Palabras clave: teoría de la subjetividad; mujeres; educación; psicología. 


\section{INTRODUÇÃO}

O transtorno mental se configura em problema individual e social e, portanto, de saúde pública tanto no Brasil como no mundo. O número de indivíduos com transtornos mentais vem aumentando, com isso gerando elevados custos sociais e econômicos para a família e para a sociedade, pois na maioria das vezes, a pessoa se sente incapacitada para o trabalho, aumentando a demanda nos serviços de saúde devido a sintomas das doenças e impactando a vida social e familiar (Organização Pan-Americana da Saúde, 2018).

No mundo, a depressão é considerada uma das principais causas de incapacidade, atingido mais mulheres do que homens, com estimativa de 300 milhões de pessoas. Os outros transtornos mentais são: Transtorno Afetivo Bipolar (com 60 milhões), Demência (50 milhões) e Esquizofrenia e outras psicoses (23 milhões) (Organização Pan-Americana da Saúde, 2018).

Por muito tempo o tratamento de pessoas com transtornos mentais foi pautado no isolamento em hospitais psiquiátricos, o que contribuiu para o afastamento dessas do convívio familiar e social. As pessoas que antes viviam enclausurados nos hospitais psiquiátricos, agora podem contar com Centros de Atenção Psicossocial (CAPS) (Santin \& Klafke, 2011). Goulart (2019) informa que os CAPS são compreendidos como sistemas subjetivos sociais, onde várias configurações sociais subjetivas estão entrelaçadas umas às outras por meio das práticas interativas, linguagens, discursos e representações sociais.

Esses locais proporcionam tratamento mais próximo de seus familiares e da comunidade onde vivem, porém ainda há uma lacuna entre o cuidado que se tem e o cuidado que se almeja ter em saúde mental (Santin \& Klafke, 2011). E ainda o tratamento dos sinais e sintomas, por meio da medicalização e do diagnóstico médico, implanta uma identidade paralisante nas pessoas com transtornos mentais e retira todos os recursos subjetivos para se abrir um novo espaço social (Goulart, 2019).

A rede de apoio psicossocial atual está em processo de alinhamento com a política de saúde mental e estratégia de reabilitação psicossocial, no entanto, há fragilidades no processo de trabalho das equipes. Muitas dessas fragilidades estão relacionadas ao déficit de recursos humanos, estruturais, de comunicação, apropriação limitada sobre suas diretrizes e o distanciamento de atividades inclusivas (Nobrega, Domingos, Silveira \& Santos, 2017).

O cuidado de pessoas com transtornos mentais, no âmbito do Centro de Atenção Psicossocial (CAPS) envolve a construção de um Projeto Terapêutico Singular (PTS), elaborado em conjunto com a equipe, família e usuário do serviço do CAPS (Ministério da Saúde, 2015). Este Projeto é um instrumento de trabalho que possibilita aos profissionais da equipe, traçarem ações que considerem a dimensão psicossocial, tendo como foco principal o indivíduo e seu contexto 
social (Ministério da Saúde, 2011). O PTS deve ser construído pelo usuário em conjunto com a equipe, incluindo uma ou mais oficinas terapêuticas objetivando resgatar sua percepção de saúde e de estabelecer estratégias que contribuam para a sua qualidade de vida (Farias et al., 2016).

Isso pode auxiliar no despertar de uma maior ou menor preocupação com sua condição física ou mental, fazendo com que o usuário perceba questões que vão além da medicalização e da doença (Farias et al., 2016, p. 149).

As oficinas são atividades grupais de socialização, expressão e inserção social, que oferecem aos usuários meios de buscar suas potencialidades valorizando os aspectos saudáveis da vida, permitindo a expressão da subjetividade através da arte, das atividades coletivas terapêuticas e da arteterapia (Farias et al., 2016).

A arteterapia é um método que utiliza várias formas de expressão artística com finalidade terapêutica, formando um canal de expressão da subjetividade humana que permite ao sujeito acessar conteúdos emocionais e retrabalhá-los através de atividade artística, ampliando suas possibilidades de expressão (Reis, 2014). Além desta compreensão, entendemos que ela é um campo de conhecimento que agrega aspectos teóricos e metodológicos que podem ser construídos com referências baseadas em abordagens distintas.

Embora existam vários materiais e linguagens expressivos considerados indutores de processos arte terapêuticos, como a colagem, a pintura e desenhos, as fotografias, os mosaicos, as maquetes, a poesia, a música, a costura, o bordado entre outros (Philippini, 2018), eles podem ser conduzidos e analisados a partir de várias referências teóricas.

Posto isso, tanto o bordado quanto a costura são artes milenares e constituem-se em trabalhos minuciosos e delicados, incluindo várias possibilidades de técnicas que promovem o desenvolvimento psicológico dos envolvidos, pois requerem capacidade de planejar, de organizar, de coordenação motora, de atenção, de memória, cognição, percepção, os quais são amalgamados por aspectos afetivos. Philippini (2018) reitera que esta atividade requer ritmo e atenção para a sequência e para o desenvolvimento de movimentos complexos. Além disso, bordar em grupo estimula a tessitura de redes de solidariedade, os quais requerem das participantes atitudes de concentração e administração do tempoespaço, e, sobretudo elas aprendem a atribuir valores aos pequenos resultados obtidos no percurso. O bordado oferece possibilidades de experimentação, tanto nas combinações das cores como nas formas.

Segundo Brun e Blasi (2016), o ato de desmanchar bordados, refazê-los ou fazer de outra forma para prosseguir nesta atividade é um desafio permanente, assim como o cotidiano da vida nos impõe. Eles ensinam que

"O movimento de baixar e levantar a cabeça, por exemplo, nos instiga a pensar a relação entre dependência, autonomia, 
liberdade. A compreensão de que o bordado pode ser um ato libertador passa pelo reconhecimento da autoria da mulher na produção artístico-cultural e dos saberes a ela associados" (Brun \& Blasi, 2016, p. 337).

Historicamente, as mulheres se reuniam nas casas umas das outras aos fins de semanas ou nos finais da tarde para conversar e bordar. Nesses encontros, que eram chamados de "rodas de bordado", umas ajudavam as outras, emprestando moldes, auxiliando na escolha das cores, tecidos, e trocavam narrativas sobre os momentos que estavam vivendo (Brun \& Blasi, 2016).

Nos dias atuais, o papel da mulher vem passando por transformações importantes na sociedade. As principais mudanças estão atribuídas à multiplicidade de funções assumidas, quanto à realização profissional, à vida afetiva, às relações familiares e outras atividades realizadas no seu dia a dia (Lopes, Dellazzana-Zanon \& Boeckel, 2014). Possivelmente, o acúmulo de funções e o aumento da jornada de trabalho contribuem para que a saúde das mulheres seja afetada, correndo o risco de desenvolver algum tipo de transtorno mental (Organização Mundial de Saúde, 2011).

Segundo Senicato, Azevedo e Barros (2018) a prevalência desses transtornos em mulheres brasileiras está entre 19 a 34\%. Valores próximos foram descobertos em uma meta-análise que avaliou pessoas entre 16 a 65 anos em todo o mundo, evidenciando que $19,7 \%$ das mulheres pesquisadas apresentavam algum transtorno mental comum (TMC) no último ano (Steel et al., 2014).

As características de mulheres mais vulneráveis ao TMC são: ter mais de trinta anos de idade, trabalhar como dona de casa, ser separadas ou viúvas, ingerir pouco consumo de alimentos naturais (frutas, verduras e legumes), ter baixa escolaridade, apresentar várias doenças crônicas e relatar algum tipo de violência (Senicato, Azevedo \& Barros, 2018).

Referindo-se às iniciativas na construção de políticas públicas que visam atender mulheres que apresentam transtorno mental, ainda são insuficientes para assistilas em suas necessidades de cuidados, pois há uma tendência na patologização dos atendimentos, com ênfase, em sua maioria, em terapias medicamentosas. Dito de outro modo, há mulheres nesta condição que, mesmo inscritas em serviços de reabilitação, são reduzidas à condição de "doentes mentais" e não como seres humanos que possuem recursos subjetivos para superarem os danos gerados por esta situação. Neste trabalho, a subjetividade é constituída nas relações sociais, as quais o sujeito é parte. Ele é ser ativo, simbólico-emocional, com possibilidades de transformar a realidade e transformar-se desde que as condições de vida forem propícias para isso. Na perspectiva cultural-histórica a subjetividade ganha outro referencial, rompendo com as bases idealistas e inatistas da compreensão do psiquismo do ser humano. González Rey e Mitjáns Martínez (2019) ensinam que 
A subjetividade é compreendida como a capacidade humana das emoções adquirirem um caráter simbólico, levando a formação de novas unidades qualitativas que constituem uma definição ontológica diferente dos fenômenos humanos, sejam eles sociais ou individuais; essas unidades expressam-se nos conceitos de sentidos subjetivo e configurações subjetivas ( $p$. 15).

Nessa abordagem, a subjetividade é um sistema que integra a subjetividade social e individual, elas articulam-se e configuram-se nas relações concretas de vida de forma mútua e não simétrica. A subjetividade social se constitui de forma singularizada nas subjetividades individuais do ser humano, a qual se expressa em suas atitudes. As subjetividades individuais integram a [...] "personalidade, a qual é entendia como configuração de configurações subjetivas" (González Rey \& Mitjáns Martínez, 2019, p. 16.) Assim, a família, por exemplo, exerce papel fundamental na constituição da subjetividade de seus integrantes. Os valores, crenças, expectativas e ações estabelecidas entre os membros expressam a qualidade das relações construídas neste grupo. Portanto, na subjetividade social de um grupo familiar aparecem expressões da subjetividade social da sociedade. Por exemplo, os estereótipos sobre o transtorno mental e a produção da incapacidade que lhe é atribuída no curso da história. (González Rey \& Mitjáns Martínez, 2019).

Portanto, no percurso de sua história o sujeito produz sentidos subjetivos no processo de subjetivação, o qual envolve os dois níveis, ou seja, a subjetividade social e individual, integrando-se às configurações subjetivas. Em tempo, o sentido subjetivo se caracteriza por sua fluidez, mobilidade e complexidade, por ser multideterminado, por falta de um termo melhor. Na versão de Anache e Martins (2019) a ação humana produz tensão entre a sua configuração subjetiva e os demais membros do grupo, conforme explicam os autores:

[...] nenhum ser humano escapa de, em sua ação, produzir tensão entre a configuração subjetiva individual e os diferentes modos de ser percebido pelas pessoas e suas relações pessoais em diferentes espaços de convivência produtores de subjetividade social: família, escola, comunidade, espaços de trabalho, espaços de lazer e outros. (p. 114)

Certamente, o transtorno mental é um fenômeno demarcado por preconceitos e o seu diagnóstico gera danos para aqueles que o receberam. Seus efeitos iatrogênicos podem promover situações incapacitantes, aprofundando o sofrimento dos envolvidos. O conceito gerador de danos refere-se às consequências que os sintomas patológicos causam, os quais impedem o ser humano de [...] "produzir novos sentidos subjetivos ante à condição que the afeta" (González Rey, 2007, p. 158).

Assim o sucesso de uma abordagem terapêutica é quando o sujeito consegue elaborar e gestar novas emoções e processos simbólicos que the dê condições de 
produzir novos sentidos subjetivos, permitindo-lhe posicionar-se de outra forma diante das relações e das atividades de seu cotidiano (González Rey, 2007). Portanto, este estudo objetiva identificar o movimento da subjetividade no processo de superação dos danos gerados pelo transtorno mental em oficina de bordado com mulheres em CAPS.

Esta pesquisa foi aprovada pelo do Comitê de Ética em Pesquisa Envolvendo Seres Humanos sob parecer no. 3.424.666 e CAAE: 15561119.1 .0000 .0021 de acordo com resolução CNS 466/2012.

\section{MÉTODO}

Este estudo fundamenta-se na Epistemologia Qualitativa (EQ) o qual busca compreender a pesquisa como um processo de comunicação e de diálogo realizado nos diversos espaços sociais em que vive, sendo o cenário onde ocorre o desenvolvimento da subjetividade de seus integrantes. Assim, a construção do conhecimento nesta perspectiva fundamenta-se em três princípios básicos (González Rey, 2017).

Um primeiro princípio foi o "Resgate do Sujeito" que defende o caráter construtivo interpretativo do conhecimento. Esse fundamento implica entender o conhecimento como produção permanente, "e não como apropriação linear de uma realidade que nos apresenta" (González Rey, 2005). Os indivíduos ou grupos são agentes ou sujeitos do processo de diálogo da pesquisa, pois todo diálogo é um processo construtivo daqueles que dele participam, mesmo que, muitas vezes, existam contradições, rupturas, abertura de caminhos, aparecendo através de novas produções subjetivas dos indivíduos em diálogo (González Rey, 2017).

Um segundo princípio é a ênfase no "caráter construtivo-interpretativo do conhecimento" que visa romper com a dicotomia entre o empírico e o teórico. Ele está associado ao tipo de problema que o estudo da subjetividade nos coloca. A ideia da pesquisa como processo teórico, interpretativo, tem como unidade principal os indicadores, ou seja, os significados que o pesquisador atribui sobre os eventos, expressões ou sistemas de expressões, os quais não parecem explícito pelos participantes de uma pesquisa. O processo de configuração de indicadores é o processo de interpretação apoiado nas informações vindas dos diferentes instrumentos e com a constante intervenção do pesquisador (González Rey, 2017). Neste sentido, o conhecimento é produção permanente, o qual o pesquisador constrói-as.

Portanto, nesta perspectiva, a pesquisa é produção permanente de conhecimento, em que o caráter processual é centrado na construção do pesquisador, implicou no rompimento da pesquisa instrumental clássica entre coleta de dados e análise da informação, representando uma mudança na forma de fazer pesquisa (González Rey, 2017). 
Um terceiro princípio foi compreender a pesquisa como "processo de comunicação dialógica", passando a ser compreendida como espaço social, sendo que múltiplos e inesperados processos de comunicação emergem espontaneamente, colocando o pesquisador e participantes como sujeitos de um processo rico em novidades. Este princípio rompe com a ideia de neutralidade do pesquisador e com a definição da pesquisa como processo teórico (González Rey، 2017).

A importância dada à comunicação no processo de construção do conhecimento baseia-se no fato de que grande parte dos problemas sociais e humanos tem raízes na comunicação entre as pessoas. Nesse sentido, a comunicação é um espaço privilegiado para o estudo da subjetividade e serve de via para conversão dos que fazem parte da pesquisa em sujeitos da pesquisa. Por isso, é de suma importância criar um cenário de pesquisa desde o primeiro encontro entre pesquisador e pesquisados formando um grupo de pesquisa fundamental para a produção da informação (Rossato \& Martinez, 2013).

A produção das informações é realizada desde os primeiros movimentos da pesquisa, gerando novas demandas de instrumentos e investigações que serão confrontadas com as anteriores, consolidando e abrindo novos caminhos investigativos, pois a definição de um indicador emerge dos significados que o pesquisador constrói dentro de um conjunto infinito de expressões vivas que só tem sentido no contexto no qual eles aparecem (González Rey, 2005).

Para entender o movimento da subjetividade no processo de superação dos danos gerados pelo transtorno mental em oficina de bordado com mulheres em CAPS, optamos pelo estudo de caso de Mariana (nome fictício), uma das participantes deste projeto que ilustra a vida de mulheres que vivem a condição de invisibilidade.

Mariana tem 51 anos, mãe de duas filhas, a filha caçula tem 33 anos e tem 3 filhos (7 e 6 anos e um bebê de 4 meses). Ficou casada com o primeiro marido por 11 anos, teve a primeira filha e depois divorciou. $O$ segundo relacionamento durou 8 anos e teve a filha caçula. Ele é falecido. $O$ terceiro relacionamento durou 11 anos e não teve filhos. Está separada a 7 anos, e desde então, não se relacionou mais com outra pessoa. Estudou até o ensino médio, mas não completou. Ela é artesã de profissão e trabalha com pinturas de aves do pantanal em cerâmicas, quadros, paredes, entre outros.

Chegou ao CAPS por encaminhamento médico e no início do ano passou a residir junto à filha na capital do estado. Anteriormente, residia sozinha em uma cidade do interior deste mesmo estado, período em que iniciou o tratamento de Transtorno de Humor.

Ao ser acolhida no CAPS, foi construído o Projeto Terapêutico Singular (PTS) junto à equipe de profissionais, considerando a identificação de algumas fragilidades como: dificuldades de relacionamento com os familiares, traumas 
psicológicos por abusos na infância, histórico de alcoolismo e dificuldades de socialização após mudança de cidade.

A estratégia utilizada pela equipe do PTS foi inseri-la em grupos terapêuticos com trabalhos manuais. Neste contexto a equipe a apresentou como uma candidata para o programa de intervenção educacional. Este Programa utilizou de uma oficina terapêutica para atender mulheres com Transtornos Mentais. Foram realizados 10 encontros, uma vez por semana, com duração aproximada de duas horas por encontro. A oficina foi composta por 6 mulheres com diagnósticos de transtornos mentais que fazem tratamento no CAPS.

A oficina foi realizada em 3 fases, a saber: Processo Educativo; Processo Construtivo (uso do bordado) e o Processo de avaliação da oficina no final da atividade. Para o processo educativo, foram abordados temas como: saúde, família, relacionamentos interpessoais e intergrupais, autocuidado, rede de apoio, entre outros. Este processo durava aproximadamente 20 minutos. A segunda fase foi o processo construtivo por meio do bordado e as participantes construíram bordados em tecido xadrez. Esta técnica foi escolhida por ser muito versátil, com pontos de simples execução, facilitando a execução e habilidade das participantes. E finalizando a oficina, o Processo de Avaliação em formato de roda de conversa usando a dinâmica conversacional.

Os instrumentos relacionados a seguir foram utilizados para oportunizar a expressão das participantes nesta pesquisa:

a) A dinâmica conversacional em grupo trabalhou os aspectos educativos sobre o adoecimento mental e experiências sócio relacionais, formando um clima favorável para as informações;

b) Os instrumentos apoiados em indutores não escritos, como o uso do bordado em tecido xadrez - construído em todos os encontros ao longo do Programa -, ilustração de desenhos, leitura de histórias, música, poesias e pinturas;

c) Os instrumentos apoiados em indutores escritos, como o complemento de frases e um momento de escrita após contar uma história.

d) Análise documental realizada no prontuário do usuário do CAPS, contendo ficha de acolhimento, Projeto Terapêutico Singular (PTS), inter(invenções) medicamentosas, evolução dos profissionais de saúde. Todos estes documentos foram utilizados como fonte de informação na caracterização do sujeito;

e) Observação, percebendo o movimento de Mariana em relação às outras participantes, com os profissionais de saúde e com a família, reforçando indicadores estabelecidos no processo da pesquisa. 
Tabela 1.

Apresentação da organização das atividades educativas por encontro

\begin{tabular}{|c|c|c|}
\hline $\mathbf{N}$ & CONTEÚDOS & INSTRUMENTOS \\
\hline 1 & $\begin{array}{l}\text { COMO EU ERA } \\
\text { ANTES DE } \\
\text { ADOECER E COMO } \\
\text { SOU AGORA. }\end{array}$ & $\begin{array}{c}\text { COMPLEMENTO DE FRASES E INSTRUMENTOS } \\
\text { APOIADOS EM INDUTORES NÃO ESCRITOS: } \\
\text { DESENHO COM GIZ DE CERA E BORDADO EM } \\
\text { TECIDO XADREZ. DINÂMICA CONVERSACIONAL } \\
\text { EM GRUPO }\end{array}$ \\
\hline 2 & $\begin{array}{l}\text { CONTO: A MINHA } \\
\text { LUA É... }\end{array}$ & $\begin{array}{l}\text { INSTRUMENTOS APOIADOS EM INDUTORES NÃO } \\
\text { ESCRITOS: POESIA: “LUAS E LUAS", DESENHO DA } \\
\text { MINHA LUA E BORDADO EM TECIDO XADREZ. } \\
\text { DINÂMICA CONVERSACIONAL EM GRUPO }\end{array}$ \\
\hline 3 & $\begin{array}{l}\text { QUAIS SÃO MEUS } \\
\text { SONHOS }\end{array}$ & $\begin{array}{l}\text { INSTRUMENTOS APOIADOS EM INDUTORES NÃO } \\
\text { ESCRITOS: MÚSICA: AZUL DA COR DO MAR (TIM } \\
\text { MAIA) E BORDADO EM TECIDO XADREZ. } \\
\text { DINÂMICA CONVERSACIONAL EM GRUPO }\end{array}$ \\
\hline 4 & $\begin{array}{l}\text { CARACTERÍSTICAS } \\
\text { DOS QUATROS } \\
\text { ELEMENTOS DA } \\
\text { NATUREZA }\end{array}$ & $\begin{array}{c}\text { INSTRUMENTOS APOIADOS EM INDUTORES NÃO } \\
\text { ESCRITOS: DESENHO COM LÁPIS AQUARELADO E } \\
\text { BORDADO EM TECIDO XADREZ. DINÂMICA } \\
\text { CONVERSACIONAL EM GRUPO }\end{array}$ \\
\hline 5 & $\begin{array}{l}\text { FAMÍLIA É QUEM } \\
\text { FAMÍLIA DIZ QUE É } \\
\text { QUEM É A SUA } \\
\text { FAMÍLIA? }\end{array}$ & $\begin{array}{l}\text { INSTRUMENTOS APOIADOS EM INDUTORES NÃO } \\
\text { ESCRITOS: DESENHO COM LÁPIS DE COR E } \\
\text { BORDADO EM TECIDO XADREZ. E INDUTORES } \\
\text { ESCRITOS: CONTAR A HISTÓRIA DO DESENHO. } \\
\text { DINÂMICA CONVERSACIONAL EM GRUPO }\end{array}$ \\
\hline 6 & $\begin{array}{l}\text { COMO VAI A SUA } \\
\text { SAÚDE? }\end{array}$ & $\begin{array}{l}\text { INSTRUMENTOS APOIADOS EM INDUTORES NÃO } \\
\text { ESCRITOS: BORDADO EM TECIDO XADREZ. } \\
\text { DINÂMICA CONVERSACIONAL EM GRUPO }\end{array}$ \\
\hline 7 & $\begin{array}{l}\text { COMO NOSSAS } \\
\text { DORES CHAMAM? }\end{array}$ & $\begin{array}{l}\text { INSTRUMENTOS APOIADOS EM INDUTORES NÃO } \\
\text { ESCRITOS: BORDADO EM TECIDO XADREZ. } \\
\text { DINÂMICA CONVERSACIONAL EM GRUPO }\end{array}$ \\
\hline 8 & $\begin{array}{l}\text { CAIXA DA DOR DE } \\
\text { MARIANA }\end{array}$ & $\begin{array}{l}\text { INSTRUMENTOS APOIADOS EM INDUTORES NÃO } \\
\text { ESCRITOS: BORDADO EM TECIDO XADREZ E CAIXA }\end{array}$ \\
\hline 9 & $\begin{array}{l}\text { O QUE GOSTAMOS } \\
\text { DE FAZER? }\end{array}$ & $\begin{array}{l}\text { INSTRUMENTOS APOIADOS EM INDUTORES NÃO } \\
\text { ESCRITOS: BORDADO EM TECIDO XADREZ. } \\
\text { DINÂMICA CONVERSACIONAL EM GRUPO. }\end{array}$ \\
\hline 10 & GRATIDÃO & $\begin{array}{c}\text { INSTRUMENTOS APOIADOS EM INDUTORES NÃO } \\
\text { ESCRITOS: VÍDEO SOBRE GRATIDÃO E O } \\
\text { BORDADO EM TECIDO XADREZ. DINÂMICA } \\
\text { CONVERSACIONAL EM GRUPO }\end{array}$ \\
\hline
\end{tabular}

Nota. Modelo extraído da pesquisa de Scalise e Anache (2019, p.145) 
Estes instrumentos possibilitaram a criação de espaços dialógicos os quais foram usados para promover a expressão das participantes ao longo de todo o processo desta pesquisa, pois eles permitiram o desenvolvimento de hipóteses apoiadas em indicadores que o pesquisador desenvolveu no curso da pesquisa (González Rey, 2011, p. 51). Essas hipóteses produziram núcleos teóricos de análise integrados ao processo geral de construção do conhecimento, que foram confrontados no percurso, servindo para reformular as hipóteses e reconstruir núcleos teóricos de análise já elaborados.

\section{RESULTADOS}

A produção das informações foi construída a partir dos relatos compartilhados na oficina terapêutica da qual a participante faz parte. Esses relatos possibilitam encontros com a história de vida de Mariana, promovendo o movimento de superação dos danos gerados pelos diagnósticos de transtornos mentais emitidos ao longo de sua vida.

As organizações das produções acerca das informações foram apresentadas em dois eixos explicativos que expressam o movimento da subjetividade no processo de intervenção durante as vivências na oficina terapêutica, a saber: (A) o processo de constituição de Mariana; (B) a oficina terapêutica bordando a vida: entre fios e desafios.

\section{A) O PROCESSO DE CONSTITUIÇÃO DE MARIANA}

\section{EU SOU FILHA DE UMA VINGANÇA}

Esta frase é a expressão que Mariana usou para se apresentar na entrevista que realizamos no início deste trabalho, a qual considerou-se como central na organização de sua história de vida. Ela relata que sua infância e o convívio com a família sempre foram conturbados. Assim casou-se aos 15 anos, teve o primeiro filho natimorto, a irmã mais velha, Mariana e irmão mais novo. Eles são em 4 irmãos, sendo cada um de um pai. Ela contou que, por vingança, seu nascimento foi uma traição da mãe com um amigo da família, pois seu esposo estava tendo um caso com a mulher desse amigo. Mariana ficou sabendo desta história aos 11 anos de idade, conforme explica no relato que segue:

Eu sou filha de uma vingança, porque o que me registrou como pai estava tendo relacionamento com uma mulher, e a mulher era amiga da família, porque ele era da aeronáutica e o marido da mulher também. Então era do mesmo círculo. E eles se juntaram para se vingar dos dois, e a vingança tá aqui, com 51 anos.

Foi um quatrilho. É! Um verdadeiro quatrilho! 
O pai que a registrou tinha problemas com alcoolismo e viajava muito a trabalho. Em sua ausência, a mãe se apaixonou por outra pessoa e engravidou.

Meu terceiro irmão, minha mãe estava apaixonada pelo cara. Diferente de mim que foi só para se vingar mesmo. E isso mexeu mais ainda com a minha cabeça, por saber que quando é só por uma traição, já é um baque. Mas quando você sabe que você além de ser da traição é de uma vingança.

Quando retornaram para a capital, a mãe conheceu outra pessoa e colocou dentro de casa. Usava sempre a desculpa que precisava ter alguém para ajudar a cuidar da casa para os filhos não passarem fome e nem necessidades. O padrasto era violento e a mãe vivia com medo das ameaças de morte caso ela se separasse dele. Registre-se que o fenômeno da violência é recorrente neste país, sendo considerado um problema de saúde pública.

\section{ENTRE DORES E DISSABORES: MARCAS DA VIOLÊNCIA}

Considerando que na perspectiva histórico cultural o sujeito se constitui por meio das suas condições concretas de vida e, deste modo, a vida que se leva é diapasão para a compreensão das diferentes formas de expressão da subjetividade. Com isso, as fontes geradoras de danos em Mariana foram as violências vivenciadas em sua infância. Ela informou que aos oito anos começou a ser molestada pelo padrasto, e em decorrência disso entrou em puberdade precoce aos nove anos de idade. Na época omitiu esta informação de sua mãe com receio de que a culpa poderia lhe ser atribuída, como declarou: "que havia se insinuado e se oferecido para ganhar algo em troca".

As crianças ou adolescentes que vivenciam o abuso, não compreendem o que está acontecendo, gerando sentimentos de vergonha, medo e culpa pelo abuso do qual são vítimas. Também ocorre o segredo existente entre a vítima e o abusador, que é intensificado pela ameaça culpabilizadora e no temor de ser incompreendida no caso de uma revelação do ocorrido (Arpini, Siqueira \& Savegnago, 2012).

A existência de abuso sexual na família afeta a convivência e as interações familiares, principalmente da relação mãe e filha, acarretando graves prejuízos emocionais e sofrimentos; passando a integrar o cotidiano e interferindo na saúde de mulheres, provocando alterações psicológicas e comportamentos autodestrutivos (Lira et al., 2017).

As relações conturbadas que sua progenitora possuía, tanto com seu padrasto quanto com a sua avó materna, afetaram Mariana decorrente das agressões no período em que ela residia com essa avó. Registre-se que a sua mãe entregou os filhos para a avó materna cuidar, com a obrigação de manter a casa financeiramente. $O$ relato que se segue ilustra o tipo de violência sofrida por Mariana: 
Ela me deixava com roupas e calçados estragados e jogava água suja de cuspe da bacia após todos escovarem os dentes de manhã [...]. Ela me tratava muito mal [...]. Então ela fazia de tudo, até que ela teve finalmente a oportunidade de chegar para mim e falar o seguinte: Se nem tua mãe gosta de você, porque que eu sou obrigada a gostar?

Quando Mariana estava com quatorze anos se envolveu com um rapaz e engravidou e, sob pressão, sua mãe a convenceu fazer um aborto. Além disso, como castigo, sua mãe lhe privou de dormir com a sua irmã no quarto, pois a considerava prostituta. A partir deste fato, ela passou a dormir no sofá da sala. Note-se que havia muita diferença no tratamento afetivo de Mariana com relação aos irmãos, conforme o relato apresentado a seguir:

Minha irmã quando fez quinze anos, ela (a mãe) mandou um buquê de flores de rosas brancas para ser entregue na escola. $\mathrm{Na}$ escola!! Não foi nem em casa, foi na escola! Eu quando fiz quinze anos, me deu uma surra de cabo de vassoura...então tem essas diferenças, né.

E de... lambuja, ela me convenceu de fazer um aborto. Eu fiz um aborto com quatorze anos. (Silêncio)

Aos quinze anos Mariana havia engravidado novamente, no entanto o pai da criança não demonstrava desejo em casar-se com ela. Esta situação agravou o seu relacionamento com sua mãe e familiares, sendo considerada prostituta. Assim, sob sucessivos atos de violências experienciadas, ela vai tecendo sua trajetória de vida. Embora Mariana tenha tentado investir no relacionamento com sua mãe, esse não é bem-sucedido, sobretudo porque sua progenitora foi arrolada como informante no processo da sua separação litigiosa, a favor do seu ex-marido. Fato que a levou a expressar seu sentimento de mágoa que nutre diante das diversas expressões de desafetos.

Ainda que o sofrimento gerado pelos valores culturais que marcam as relações sociais da família de Mariana, ela os considera fundamentais para gerenciar sua vida, assim, há esforços dispendidos para sobreviver entre as formalidades e as rejeições de sua progenitora, irmãos e filhas. Esses se constituem indicadores de sentidos subjetivos que se expressam por meio de sentimentos de raiva e de culpa gerados nas situações violentas, os quais foram adquirindo centralidade na constituição da subjetividade de Mariana.

É neste labirinto que Mariana foi se constituindo e construindo suas relações com filhas e netos, os quais, são descritos por ela como conturbados, sobretudo quando se refere à sua primeira filha, com quem reside atualmente. Em seus relatos, Mariana declara ter mais afinidade com a sua segunda filha, uma vez que se assemelham tanto na forma física quanto nas características pessoais. Suas histórias se coincidem, pois, aos quinze anos, ela (segunda filha) engravidou e foi morar na aldeia com o pai da criança, pois ele pertence à etnia Terena. Do mesmo modo, elas experimentaram a pressão da família. Diante do 
aprofundamento da crise, essa filha retorna para casa grávida do segundo filho, e o seu nascimento impactou Mariana, quando então inicia o seu tratamento psiquiátrico decorrente do quadro depressivo em consequência de várias tentativas de suicídio, conforme o relato que se segue:

Até que veio a segunda bomba: Raoni. E você fala daquela música que mexe com você, o Raoni nasceu no dia 31 de julho, no dia do show da Sandra de Sá e a música que eu mais gosto dela é aquela: Solidão, dá um tempo e vai saindo, meu amor está... sabe? E foi bem na época que eu comecei o tratamento da depressão.

As relações de dependência vão se estabelecendo a partir deste fato, pois Mariana e seus netos precisaram residir na capital, sob a tutela da sua primeira filha, pois a mãe dessas crianças vive com seu atual marido e uma filha recémnascida. Esta situação causa desconforto para a família e sobretudo para Mariana que, por recomendação do médico psiquiatra, precisa de acompanhante.

Dentre os danos gerados pelo "Transtorno Mental", a perda da sua autonomia foi a mais impactante, pois implicou em abandono das atividades laborais que desempenha em uma cidade turística do interior do estado e a restrição a sua liberdade de expressão, como registra em seu relato: "Eu não consigo falar por um motivo. Por mais que fala: você está na casa da sua filha. Exatamente, eu estou na casa da minha filha! Eu não estou na minha casa! "

Além disso, Mariana convive com as dores decorrentes de um acidente que the provocou múltiplas fraturas, dentre elas destacam-se as fraturas craneanas, na bacia, na cabeça do fêmur, no acetábulo direito (depressão na pelve), entre outras. Na época, não conseguiu fazer o tratamento de forma adequada, pois acredita que a assistência médica não foi suficiente para resolver o problema e hoje relata sentir muitas dores pelo corpo.

Nas encruzilhadas deste labirinto, o trabalho que, ao mesmo tempo se apresenta como estruturante, passa a ser considerado fonte de tensão mediante os limites impostos pela sua condição física e mental. Dito de outro modo, quando se sente pressionada pelo volume de encomendas de artesanatos que precisa produzir em série, Mariana se ressente de perder sua criatividade artística, o que Ihe causa desconforto. Em tempo, suas atividades artísticas são pinturas em cerâmicas com motivos regionais, conforme ilustra o diálogo que se segue:

Mariana: De ver todo aquele material ali na frente e ver aquela obrigação "eu preciso fazer, preciso fazer, meu tempo está se esgotando". É porque eu não fiz antes. Então já vem o sentimento de culpa.

Pesquisadora: Você está trazendo para nós que quando tem uma atividade de trabalho para entregar você sente culpa, é isso? 
Mariana: A pressão...eu não estou mais conseguindo lidar com a pressão (silêncio). Se eu me sinto pressionada de alguma forma, eu perco um pouco o equilíbrio [...] ou por também não conseguir fazer a quantidade que eu produzia antes. Então tem os dois, os dois. Eu ter menos trabalho, do que eu tinha. Eu chegava a pintar cinquenta caneca em uma noite. Chegava seis horas da tarde, tem cinquenta caneca, quando era meia noite estava tudo pronto.

Se por um lado, o trabalho é fonte de realização, por outro, quando tem que produzir em série se sente pressionada para finalizar as encomendas. Esta polarização impacta o seu rendimento laboral, e, consequentemente implicando na diminuição da renda familiar, a qual tem sido fonte de conflito com a sua primeira filha. Não obstante, há investimentos desta filha para ofertar condições de trabalho para sua mãe, pois construiu um quarto em sua casa, sendo o lugar que ela divide para dormir e confeccionar os artesanatos, os quais constituem sua principal fonte de subsistência. Assim, o trabalho é o seu "porto seguro" e ao mesmo tempo fonte de tensões e conflitos.

Parece que vivo uma mentira, uma casca vazia, vejo meu trabalho que tanto me dá prazer, hoje está abandonado. Preciso, quero voltar a me realizar com meu trabalho, pois foi e é ele que consigo voltar a sonhar, ser o que fui no passado, ter a minha vida de volta.

A sua rotina limita-se a produzir as encomendas em seu quarto, assistir programas de televisão, acessar a internet e cumprir os rituais de sua religião atual, pois se converteu ao Islamismo após sua crise depressiva, a qual tem sido um escudo de proteção, pois faz uso de indumentária característica dessa religião (hijab ou véu) e faz as orações diárias quando possível. Portanto, a oficina de bordado no CAPS configura como uma das vias de acesso ao convívio com outras pessoas e permitiu a produção de sentidos subjetivos sobre: as suas relações familiares, a sua relação com seu trabalho e seus cuidados com a saúde.

\section{B) ENTRE FIOS E DESAFIOS: AS TISSITURAS DAS INTER (INVENÇÕES)}

A oficina de bordado concebe como espaço para expressão da subjetividade, onde circulam valores culturais compartilhados por meio do diálogo, interação, reciprocidade, vínculos entre os participantes desta atividade, da qual a pesquisadora é ativa no processo de pesquisa. Nesse sentido, o termo inter(invenção) está sendo empregado para firmar a concepção de que o êxito do trabalho terapêutico se viabiliza quando se possibilita condições para a emergência do sujeito, mobilizando com isso o desenvolvimento da subjetividade. Segundo González Rey (2016, p. 185, tradução nossa) a subjetividade se organiza 
[...] como uma configuração complexa de sentidos subjetivos que é caracterizada por um fluxo nos quais processos simbólicos e emocionais aparecem juntos a uma nova qualidade diferenciada de todos os processos que participam em sua gênese. Essas unidades simbólico-emocionais especificam o caráter ontológico da experiência humana.

O desenvolvimento humano é dinâmico, se constitui no movimento das relações sociais, portanto ele é histórico-cultural. Neste percurso o ser humano aprende a linguagem e outras ferramentas culturais, possibilitando-Ihe participar ativamente das atividades culturais da comunidade. Nos dizeres de Rossato e Assunção (2019), o fato de estar em um grupo ao mesmo tempo não é fator determinante para mobilizar a produção de sentidos subjetivos, "senão pela qualidade das produções subjetivas que gera em seu viver" (Rossato \& Assunção, 2019, p.53). Para as autoras, elas são mobilizadas graças os recursos simbólicos-emocionais produzidos por meio das vivências dos envolvidos.

Nesta perspectiva o desenvolvimento subjetivo é um processo particular de cada sujeito, se caracteriza pela contradição, irregularidade, não, possui estágios demarcados, vez que depende das condições de vida de cada um. Para González Rey (2017), este processo se constitui de várias formas, por estarem associadas aos surgimentos de novas configurações subjetivas. Cada participante das oficinas, mediante as mesmas atividades (bordado), munido de suas ferramentas culturais podem gerar diferentes formas de subjetivação, tornando-o protagonista do seu processo de desenvolvimento. Em tempo, a cultura representada é um sistema subjetivo gerador de subjetividade (González Rey, 2003, p. 78).

Os sentidos subjetivos representam a unidade simbólico-emocional que se constituem nas vivências do sujeito. Em tempo, o conceito de vivência (perejivânie), segundo Vinha e Welcman (2010), Vygotsky expressa a unidade entre afeto e intelecto, a qual se produz na situação social em que o sujeito participa e é afetado pelos eventos que ali ocorrem, conforme Toassa ensina "as vivências, na língua russa, não são experiências indiferentes, envolvem necessariamente qualidades emocionais, sensações e percepções, acarretando uma imersão do sujeito" (Toassa, 2011, p. 34-35). Assim, as oficinas constituem espaços de encontro e confronto de vivências, onde é possível aprender e ensinar, intercambiando conhecimentos e construindo saberes nas relações que elas oportunizam.

A produção de novos sentidos subjetivos permite alterar a rede de sentidos subjetivos original, conduzindo este sujeito à produção de outras configurações subjetivas. Sendo assim, "não é a vivência de um fato em si que importa, mas como o sujeito, imbricado na experiência vivida, subjetiva essa experiência" (Rossato, Martins \& Martínez, 2014, p.39).

Segundo González Rey (2011, p. 23) as configurações subjetivas "são formações psicológicas que sintetizam tanto a pluralidade de experiências de uma história vivida, como os múltiplos contextos sociais que se atualizam na experiência 
presente de uma pessoa ou grupo social". Assim, a "cada ponto, um conto" é possível identificar as configurações subjetivas da participante, as quais foram sendo tecidas sob tensões e conflitos desde a sua concepção. As situações de violência e abandono foram sendo atualizadas no percurso das atividades proporcionadas pela oficina de bordado as quais permitem à Mariana espaço para expor suas vivências sem ser punida ou mesmo cerceada, conforme ela mesma declara:

Isso aqui para mim é liberdade. Porque aqui eu posso tá falando o que eu tô sentindo, como está a minha situação e sem ser apontada. A oficina me faz sentir livre! [...] Aqui a gente vai se soltando [...] é um momento nosso, sem interferência de lá de fora.

Por permitir a liberdade e a criatividade das pessoas, as inter(invenções) produzidas nas oficinas se constituem como espaço para o aprendizado e para a experimentação de atividades que nem sempre se têm a oportunidade de realizálas (Farias et al., 2016). Portanto, o bordado é uma atividade indutora que tem como objetivo promover a comunicação entre a pesquisadora e a participante, conforme os dizeres de Mariana:

A gente fala aqui, coisas que nós não podemos falar lá fora. Porque se a gente for falar lá fora, com certeza não vai ser boa coisa para a gente. De uma maneira ou de outra, vai sobrar um resquício de mágoa, vai aflorar alguma coisa do passado na cabeça daquela pessoa.

As inter(invenções) terapêuticas na oficina foram tecidas por meio de diálogo, com o objetivo de construir relações de reciprocidade e de confiança, permitindo compreender o processo de adoecimento e os danos gerados por ele. Este cenário ajusta ambiente propício para transformar os conhecimentos trazidos do senso comum em conhecimentos científicos sobre as condições que lhes afetam. Paulatinamente, os problemas foram se tornando desafiadores para Mariana, gerando condições de desenvolvimento subjetivo, o qual pode ser identificado nas situações em que apresentávamos algumas histórias para reflexões. Nestas oportunidades, identifica-se a qualidade das suas funções psicológicas como memória, atenção, cognição, sensopercepção, consciência e pensamento e de seus recursos emocionais para superá-los.

Apresentaremos a seguir os indicadores de mudanças qualitativas de Mariana neste processo, as quais podem ser identificados em suas relações com os membros de sua família, dentre os quais destacam-se os netos. Sobre isso ela relata que consegue expressar afeto, abraçando-os, atitude que outrora seria impossível de realizá-la. Note-se que a participante tem condições de perceber o seu progresso, atribuindo-o para processo vivenciado na oficina de bordado.

Acredito que sim, a oficina me ajuda a derrubar o muro que construí com a minha família, tinha medo do toque, do afeto 
sem cobrança, ela me ajuda a melhorar o afeto com os meus netos.

Com relação ao seu estado de saúde mental gerado ao longo da sua vida, Mariana consegue identificar os seus limites e, por conseguinte; sabe que pode buscar atendimento no CAPS, demonstrando controle da situação e autonomia para tomar decisões sobre suas escolhas. Neste sentido, a oficina de bordado se constitui como âncora, pois exerce função estruturante e educativa, conforme o relato da participante.

Aqui, onde eu encontro equilíbrio, o bordado...o grupo...a dinâmica me traz um equilíbrio que eu não tenho, que eu não tinha e que eu estou aprendendo a ter. Tá me fazendo mudar e repensar muita coisa [...]

Mariana expressa nas conclusões das atividades da oficina de bordado, as mudanças que consegue identificar sobre sua relação com o trabalho, pois não sente mais pressionada pelas encomendas dos artesanatos, os quais são fundamentais para sua subsistência, pois consegue ter mais concentração nas atividades laborais mesmo em situações de crises de ansiedade.

Estou diferente, me sinto bem com o meu trabalho, provavelmente com o bordado, algo totalmente diferente tenha feito isso. Sou artesã e sei que meu trabalho é bom, [...] sempre estão me perguntando quando vou voltar, pois, tenho serviço, não me sinto pressionada e olha que é muito trabalho

Infere-se que, a pressão que a participante sentia em decorrência das encomendas de artesanatos está associada às suas vivências em situações de violência experimentadas na vida. Nesse sentido, Mariana expressa em vários momentos das atividades que tem consciência de seus progressos, realizando reflexões sobre eles, conforme o excerto dos registros documentais da pesquisa:

Tô me fortalecendo! Principalmente aqui com vocês. Vocês não sabem a diferença que estão fazendo. É sutil por enquanto, mas a diferença...eu vejo a diferença em mim. Dos meus pensamentos, das minhas atitudes, eu já estou começando a contornar alguns obstáculos. Eu quero agradecer a vocês.

Em um outro encontro trabalhamos com a pergunta: "como era antes do seu adoecimento mental e como é agora?", e Mariana expressa que ela "era uma sombra", onde seus olhos verdes se destacavam. Ela relata que não tinha identidade, pois era sempre considerada como: a irmã de "fulana", a filha da "beltrana", a neta da dona "siclana".

Eu era uma sombra. Eu já era a ovelha negra da família. artesanato me deu uma identidade, eu passei a ser reconhecida como uma pessoa, já não era mais a sombra de alguém.

Ela acredita que sua doença mental é desde a infância, pois havia isolamento mental, tristezas, falta de vontade de realizar atividades. Essa perspectiva, na via 
da despatologização, compreende que o transtorno mental é uma configuração subjetiva em processo de produção da vida. Ele ganha sentido no movimento entre a subjetividade social e individual, e, com isso gera outra forma de organização da vida psíquica. Assim, o sintoma é uma forma de manifestação de configuração subjetiva particular que resulta da vivência de cada pessoa (Goulart, 2019).

Nesse sentido, o processo de adoecimento de Mariana e as inter(invenções) pelas quais vivenciou, foi dando-lhe oportunidade para construir um novo caminho, saindo da sombra e se apresentando como sujeito de sua vida, pois devido a esse percurso foi possível aprender a construir outros caminhos para superar a condição imposta pelos danos gerados pelo diagnóstico de transtorno mental. Segundo González Rey (2003) a aprendizagem é um processo de produção de sentido do sujeito que aprende, o qual envolve as dimensões cognitivas e afetivas.

Carrego muitas experiências e conhecimento, mas não são todos que têm ou podem ouvir. Viver ao modo que a grande maioria, para quem como eu, que não segue as regras da sociedade, os julgamentos, as cobranças; minaram minha capacidade de sonhar, de ser quem eu sou realmente.

Os espaços de aprendizagem promovidos pela oficina de bordado favorecem condições para que a participante amplie seu interesse para voltar a sonhar e a desejar superar as adversidades.

No bordado, as histórias de vida abrem caminho para novas histórias e novos bordados, e na mistura das linhas e das cores, as formas aparecem e acendem nossas memórias. Assim, "no espiral da vida, a vida é bordada, o bordado cria vida que inspira um novo bordado" e é nesse movimento que a vida acontece (Brun \& Blasi, 2016).

\section{CONSIDERAÇÕES FINAIS}

Propor um trabalho fundamentado na perspectiva cultural-histórica, o qual tem como referência os aportes da Epistemologia Qualitativa se apresentou como um caminho promissor para a construção de formas de inter(invenção) no campo da saúde mental, vez que proporciona aos seus participantes condições para que possam tomar posse da sua vida, na medida em que reconhecem os danos gerados no curso das suas experiências vividas.

A arte como ferramenta cultural é um espaço rico em conteúdos simbólicosemocionais, os quais afetam os seus integrantes de forma diferenciada. Por exemplo, foi ofertada às participantes da oficina atividades similares de bordado, e cada uma delas produziu desenhos diferentes, os quais foram tecidos em meio a lágrimas e a sorrisos provocados por conteúdos afetivos diversificados. O que nos permite afirmar neste lugar, eivados de conhecimentos, emoções, encontros 
e confrontos com a saúde/doença mobilizam conteúdos simbólico-emocionais, torna-se uma unidade basilar para o desenvolvimento da subjetividade da participante.

Na singularidade de Mariana é possível identificar o movimento do universal no particular. A sua história, a sua condição de mulher expurgada em sua gênese duplamente, por representar as relações matrimoniais falidas e ao mesmo tempo evidencia as marcas das relações de gênero engendradas na sua cultura. Mediante às condições disponíveis ela se apresenta com suas forças e fragilidades, reconhecida por ela e pelos seus familiares por esta última característica.

Portanto as inter(invenções) realizadas consideram os elementos de sentidos subjetivos que aparecem na tessitura de cada fio, as quais são valorizados e compartilhados entre os demais, dentre os quais destacam-se: o não julgamento das suas ações; a busca de alternativas para construir outros caminhos para o enfretamento dos danos gerados pela sua condição de saúde mental; envolvimento em atividades que despertem o seu interesse; proporcionar condições para Mariana expresse os seus sentimentos, seus amores e dissabores. Nesse sentido o profissional exerce a função de âncora, e com tal promove a estabilidade para que seja possível ganhar forças para a elaboração de outros caminhos.

\section{REFERÊNCIAS}

Arpini, D. M., Siqueira, A. C., \& Savegnago, S. D. O. (2012). Trauma psíquico e abuso sexual: O olhar de meninas em situação de vulnerabilidade. Psicologia: Teoria e prática, 14(2), 88-101.

Anache, A. A., \& Martins, L. R. R. (2019). Subjetividade social em relação à educação especial e os desafios da formação docente. In M. Rossato, V. L. A. Peres (Eds.), Formação de educadores e psicólogos: Contribuições e desafios da subjetividade na perspectiva cultural-histórica. (pp. 69-811). Curitiba, PR: Appris.

Ministério da Saúde. Centro de Estudo e Pesquisa em Saúde Coletiva. (2011). Guia Prático de matriciamento em saúde mental. Brasília, DF. Disponível em http://bvsms.saude.gov.br/bvs/publicacoes/guia_pratico_matriciamento_saudeme ntal.pdf

Ministério da Saúde. Secretaria de Atenção à Saúde. Departamento de Atenção Especializada e Temática. (2015). Centros de Atenção Psicossocial e Unidades de Acolhimento como lugares da atenção psicossocial nos territórios: orientações para elaboração de projetos de construção, reforma e ampliação de CAPS e de UA. Brasília, DF. Disponível em http://bvsms.saude.gov.br/bvs/publicacoes/centros_atencao_psicossocial_unidade s_acolhimento.pdf

Brun, M., \& Blasi, M. (2016). Quando o bordado e as histórias das mulheres se encontram. Coisas do Gênero: Revista de Estudos Feministas em Teologia e Religião, 2(2), 335349. 
Farias, I. D., Thofehrn, M. B., Andrade, A. P. M., Carvalho, L. A., Fernandes, H. N., \& Porto, A. R. (2016). Oficina terapêutica como expressão da subjetividade. SMAD. Revista Eletrônica Saúde Mental Álcool e Drogas 12(3), 147-153. doi:10.11606/issn.18066976.v12i3p147-153

Fhilippini, A. (2018). Linguagens, materiais expressivos em arteterapia: Uso, indicações e propriedades. Rio de Janeiro, RJ: Wak Ed.

González Rey, F. L. (2003). Sujeito e subjetividade: Uma aproximação histórico-cultural. São Paulo, SP: Thomson Learning.

González Rey, F. L. (2005). Pesquisa qualitativa e subjetividade: Os processos de construção da informação. São Paulo, SP: Pioneira Thomson Learning.

González Rey, F. L. (2007). Psicoterapia, subjetividade e pós-modernidade: Uma aproximação com a perspectiva histórico-cultural. São Paulo, SP: Thomson Learning.

González Rey, F. L. (2011). Subjetividade e saúde: Superando a clínica da patologia. São Paulo, SP: Cortez.

González Rey, F. L. (2016). Advancing on the topics of the social and subjectivity from a cultural-historical approach: Moments, paths and contradictions. Journal of the Theoretical and Philosophical Psychology, 36, 175-189.

González Rey, F. L., \& Martinez, A. M. (2017). Subjetividade: Teoria, epistemologia e método. Campinas, SP: Editora Alínea.

González Rey, F. L., \& Mitjáns Martínez, A. (2019). A preparação para o exercício da profissão docente: Contribuições da teoria da subjetividade. In M. Rossato, \& V. L. A. Peres (Eds.), Formação de Educadores e psicólogos: Contribuições de desafios da subjetividade na perspectiva cultural-histórica (pp. 13-46). Curitiba, PR: Appris.

Goulart, D. M. (2019). Saúde mental, desenvolvimento e subjetividade: Da patologização à ética do sujeito. São Paulo, SP: Cortez.

Lira, M. O. S. C., Rodrigues, V. P., Rodrigues, A. D., Couto, T. M., Gomes, N. P., \& Diniz, N. M. F. (2017). Abuso sexual na infância e suas repercussões na vida adulta. Texto \& Contexto - Enfermagem, 26(3), e0080016. doi:10.1590/0104-07072017000080016

Lopes, M. N., Dellazzana-Zanon, L. L., \& Boeckel, M. G. A. (2014). Multiplicidade de papéis da mulher contemporânea e a maternidade tardia. Trends in Psychology, 22(4), 917-928. doi:10.9788/TP2014.4-18

Nobrega, M. P. S. S., Domingos, A. M., Silveira, A. S. A., \& Santos, J. C. (2017). Tecendo a rede de atenção psicossocial oeste do município de São Paulo. Revista Brasileira de Enfermagem, 70(5), 965-972. doi:10.1590/0034-7167-2016-0566

Organização Mundial da Saúde. (2011). Mulheres e saúde: Evidências de hoje, agenda de amanhã. Brasília, DF: Disponível em https://www.who.int/eportuguese/publications/Mulheres_Saude.pdf?ua=1

Organização Pan-Americana da Saúde (2018). Determinantes sociais e riscos para a saúde, doenças crônicas não transmissíveis e saúde mental: Folha informativa transtornos mentais. Brasília, DF. Disponível em https://www.paho.org/bra/index.php?option=com_content\&view=article\&id =565 2:folha-informativa-transtornos-mentais\&ltemid =839

Reis, A. C. (2014). Arteterapia: A arte como instrumento no trabalho do psicólogo. Psicologia: Ciência e Profissão, 34(1) 142-157. https://doi.org/10.1590/S141498932014000100011 
Rossato, M., \& Martinez, A. M. (2013). Desenvolvimento da subjetividade: Análise de histórias de superação das dificuldades de aprendizagem. Psicologia Escolar e Educacional, 17(2), 289-298.

Rossato, M.; Martins, L. R. R., \& Martinez, A. M. (2014). A construção do cenário social da pesquisa no contexto da epistemologia qualitativa. In A. M. Martinez, M. Neubern, V. D. Mori (Eds.), Subjetividade contemporânea: Discussões epistemológicas e metodológicas (pp. 35-59). Campinas, SP: Alínea.

Rossato, M., \& Assunção, R. (2019) O desenvolvimento subjetivo no processo da formação docente. In M, Rossato, V. L. A. Peres (Eds.), Formação de educadores e psicólogos: Contribuições e desafios da subjetividade na perspectiva culturalhistórica (pp. 47-67). Curitiba, PR: Appris.

Santin, G., \& Klafke, T. E. (2011). A família e o cuidado em saúde mental. Barbaroi, (34) 146-160.

Scalise, L. N., \& Anache, A. A. (2019). A ação docente na pós-graduação sob a perspectiva cultural histórica: A criatividade em foco. Obutchénie: Revista de Didática e Psicologia Pedagógica. 3(1), 135-157. doi:10.14393/OBv3n1.a2019-50594

Senicato, C., Azevedo, R. C. S, \& Barros, M. B. A. (2018). Transtorno mental comum em mulheres adultas: Identificando os segmentos mais vulneráveis. Ciência \& Saúde Coletiva, 23(8), 2543-2554. doi:10.1590/1413-81232018238.13652016

Steel, Z., Marnane, C., Iranpour, C., Chey, T., Jackson, J.W., Patel, V., \& Silove, D. (2014). The global prevalence of common mental disorders: A systematic review and metaanalysis 1980-2013. Internacional Journal of Epidemiology, 43(2), 476-493. doi: 10.1093/ije/dyu038

Toassa, G. (2011). Emoções e vivências em Vigotski. São Paulo, SP: Papirus.

Vinha, M. P., \& Welcman, M. (2010). Quarta aula: a questão do meio na pedologia, Lev Semionovich Vigotski. Psicologia USP, 21(4), 681-701. doi:10.1590/S010365642010000400003

\section{AGRADECIMENTOS}

As autoras agradecem as mulheres participantes do: Programa de Intervenção Educacional com Mulheres com Transtorno Mental na Promoção do Desenvolvimento da Subjetividade.

\section{SOBRE AS AUTORAS}

Priscila Maria Marcheti, enfermeira, mestrado em Saúde e Desenvolvimento do Centro Oeste. Doutoranda pelo Programa de Pós-Graduação em Educação da Universidade Federal do Mato Grosso do Sul (UFMS). Professora Assistente do Instituto Integrado de Saúde/INISA - Universidade Federal do Mato Grosso do Sul (UFMS). Campo Grande - MS. http://orcid.org/0000-0002-1662$\underline{4139}$ e-mail: priscila.fiorin@gmail.com

Alexandra Ayach Anache, psicóloga, mestrado em Educação pela Universidade Federal de Mato Grosso do Sul (UFMS) e doutorado em Psicologia Escolar e do Desenvolvimento Humano pela Universidade de São Paulo (USP). Pós-Doutorado em Educação na Universidade de Brasília. Professora Titular do Centro de Ciências Humanas e Sociais da Universidade Federal de Mato Grosso do Sul. Campo Grande - MS. https://orcid.org/0000-0002-7937-4448 e-mail: alexandra.anache@gmail.com 